\title{
FURTHER ECONOMETRIC EVIDENCE ON THE EXTENT AND SOURCES OF COST SAVINGS IN COMPETITIVELY TENDERED CONTRACTS*
}

Jorge González Chapela, ${ }^{\dagger}$ José M. Labeaga, ${ }^{\dagger}$ Luis A. Medrano ${ }^{\S}$

This version: August 2016

\begin{abstract}
By estimating a flexible nonlinear regression model of savings on an original data set of service procurements conducted by the Spanish Armed Forces, this paper provides robust and precise novel econometric evidence on the extent and sources of cost savings in public procurement. The net effect on savings of the policy-amenable and economically advantageous variables that we estimate, such as the size of the procured function, the importance of price in the contract award criteria, and the number of bidders who participate in the tender, may help contracting agencies to select management practices and to forecast the price paid out. A comparison with estimates reported in previous studies is also made.
\end{abstract}

Keywords: Public procurement; size elasticity of savings; exponential regression; Spanish Armed Forces. JEL codes: H57, C51.

\footnotetext{
* We are indebted to Andrés Magallón for invaluable advice throughout this project. Thanks also to Jorge Rosell for encouragement and to Manuel García, Juan Carlos Soto, and Ricardo Bueno for helpful comments. This research was supported by Centro Universitario de la Defensa de Zaragoza Grant 2015-06.

${ }^{\dagger}$ Centro Universitario de la Defensa de Zaragoza. Address: Academia General Militar, Ctra. de Huesca, s/n, 50090 Zaragoza, Spain. Email: jorgegc@unizar.es. Ph: (+34) 976739834. Corresponding author.

$\$$ Department of Economic Analysis II, National Distance Education University. Address: Senda del Rey 11, 28040 Madrid, Spain. Email: jlabeaga@cee.uned.es. Ph: (+34) 913987811. $\S$ Centro Universitario de la Defensa de Zaragoza. Address: Academia General Militar, Ctra. de Huesca, s/n, 50090 Zaragoza, Spain. Email: 1medrano@unizar.es. Ph: (+34) 976739839.
} 


\section{INTRODUCTION}

Procurement is much used by public administrations (firms and international institutions) to buy goods with specific characteristics. Currently, for example, public procurement in the European Union is estimated to account for about $14 \%$ of GDP. ${ }^{1}$ Despite the extent to which procurement is used in the public sector, relatively few studies (prominent among which are Domberger et al. 1986, Snyder et al. 2001, and Decarolis 2014) have attempted to provide econometric evidence on the extent and sources of cost savings (namely the reduction in the amount paid by the government to procure the good) in competitive tendering.

This study is motivated by several interesting features of both the original data set on service procurements conducted by the Spanish Armed Forces (SAF) that we have compiled and the econometric methodology that we have employed, which lead us to believe that significant efficiency and managerial lessons can be learned from its results. For one thing, our measure of savings includes only savings derived from competition between bidders. By contrast, savings measures derived from privatization competitions of the kind encouraged by the U.S. Commercial Activities program by definition combine savings from competition and savings from privatization (see, e.g., Carrick 1988 and Snyder et al. 2001). As such, the lessons derived from the results obtained in this paper are therefore better suited to situations in which the service to be procured is not being provided in-house.

Second, we estimate a savings regression model on a relatively rich set of characteristics of procurements, including the estimated cost of the service (or reserve price), the weight given to price in the contract award criteria, and, for a subsample of procurements, information on the number of bidders who participated in the tender. To the best of our knowledge we are, for example, the first to use actual data to estimate the opportunity cost of (i.e. the reduction in

\footnotetext{
${ }^{1} \mathrm{http}: / /$ ec.europa.eu/growth/single-market/public-procurement/index_en.htm.
} 
savings brought about by) introducing dimensions other than price into the award criteria, which is the distinctive feature of the European Union's “best economic value" contract award system. Last but not least, we precisely estimate a flexible nonlinear regression model of savings which is then tested against a variety of specification failures.

On the other hand, this paper suffers from some limitations which need to be taken into account when drawing policy conclusions from its results. Prominent among them is the fact that the econometric model that we estimate does not include information on contractors' actual performance but rather some controls for ex-ante quality of service (Domberger et al. 1995) plus a measure of bid screening intensity by the contract awarding committee (Decarolis 2014). To the extent that these controls are, as a matter of fact, insufficient to account for the risk of poor performance by contractors, our estimates would tend to overstate the magnitude of, and the effects on, true savings (note, however, that the evidence on the effect of competition on performance is somewhat mixed: See the references below.)

Furthermore, the paper focuses on estimating the net effect of covariates on savings, which precludes forecasting the effects of regime shifts that are not reflected in the data. For example, from our results one cannot predict the impact on savings of a change in certain competition rules (e.g. an increase in the financial guarantee to be given by the winning bidder), or a change in market structure that goes beyond a variation in the number of actual competitors. Nevertheless, for the reasons given above, we think that we provide robust and precise further evidence on economically advantageous determinants of savings, some of which are amenable to policy change.

In the field of Defense, due partly to the scarcity of adequate data (MacDonald 2010), nearly all of the few studies that have attempted to measure the extent and sources of cost savings associated with competitive tendering analyze U.S. Department of Defense data and report savings in the range of 20-30\% per year (see Carrick 1988, Snyder et al. 2001, 
Domberger et al. 2002, and Lyon 2006). ${ }^{2}$ We are aware of only one other Defense-specific study of cost savings, conducted in Spain (Fernández Roca 2011). The author of this last study reports a relatively small savings rate $(4 \%)$ in contracting out the maintenance of helicopters used by the SAF, but this figure did not result from competitive bidding but from more centralized procurement.

The rest of the paper is organized as follows: Section 2 provides background on public procurement in Spain during the period covered by this analysis. Section 3 reviews the data and the construction of the main variables. Section 4 describes the estimation framework and Section 5 presents the econometric results. Section 6 offers the main conclusions.

\section{PUBLIC PROCUREMENT IN SPAIN UNDER THE 2011 LAW}

From December 16, 2011 to approximately the first half of 2016, procurement by the Spanish government (including the armed forces) took place under Royal Legislative Decree 2011/3. This legislation was enacted to consolidate all the modifications made to the previous public procurement regulations (Public Sector Contracts Act 2007/30), and to substantially reduce government agencies' discretionary power to modify contract provisions after awarding the contract (see Gris González 2012).

During the lifetime of the 2011 law, the procurement process began with a contracting agency issuing an administrative inquiry in order to prove the need for the service (work or supply) to be procured. After receiving authorization to procure, but before choosing the awarding mechanism, the agency had to estimate the contracting dossier value. This was calculated as the estimated cost net of VAT plus the cost of possible options and renewals and possible bonuses paid to bidders. The cost estimated by the agency indicated the maximum

\footnotetext{
${ }^{2}$ The study by Domberger et al. (2002) uses New Zealand Army data.
} 
price to be paid out (excluding options, renewals, and bonuses), and was intended to reflect the general market price of the service to be procured.

Whenever a contracting dossier for a service was valued at $€ 18,000$ or more, it had to be purchased ordinarily by a procurement process open to any interested provider. ${ }^{3}$ The winning bidder was determined by means of a sealed-bid auction in which one of two different award criteria could be employed: lowest cost or best economic value. The former criterion implied that the contract would be awarded to the lowest bidder provided the bid was no higher than the cost estimate. Best economic value was used whenever the procurement involved dimensions in addition to price. In this case, each individual dimension of a quote would be evaluated and assigned a score, and the contract would be awarded to the supplier who submitted the quote with the highest score according to a pre-specified scoring rule.

For example, in a procurement for the maintenance of a military base's water supply system included in our sample, the score assigned to bidder $j$ 's quote was calculated as

$$
\text { Score }_{j}=0.7 \times \text { Price }_{j}+0.2 \times \text { Response }_{j}+0.1 \times \text { Standard }_{j},
$$

where Price $_{j}=10 \times \frac{\text { Lowest bid }}{\text { Bid }_{j}}$, Response $_{j}$ took the value 5 (10) if $j$ 's offered time to restore water supply in case of a breakdown was 1 hour ( 2 hours) less than the maximum permitted time, and Standard ${ }_{j}$ equaled 10 if $j$ certified ISO 9001 standard quality management. In both lowest cost and best economic value systems a tie was broken by randomizing equally over the bidders with the best bid.

\footnotetext{
${ }^{3}$ When the contracting dossier value was difficult to pinpoint, there was overriding urgency, or a contract had previously been declared void, among other circumstances, the purchase could be negotiated with at least three potential providers. When a contracting dossier for a service was valued at less than $€ 18,000$, the agency could directly select the company to buy from.
} 
In cases where it was possible to provide the service to be procured separately but it still constituted a functional unit (e.g. the maintenance of buildings located at different military bases), the whole contracting dossier could be divided into batches. Providing that the whole dossier was valued $€ 18,000$ or more, each batch had to be purchased ordinarily by procurement of the types described above (even if the cost estimate for a batch was lower than $€ 18,000$ ).

Several provisions were included in the 2011 law which were aimed at eliciting unbiased bids and limiting the risk of poor performance by contractors. One of those provisions was the possibility of requiring the winning bidder to prove the price that it offered if that price was judged to be abnormally low by the contract awarding committee. In the event that its explanations were deemed unreliable, the winning bidder would be disqualified and (typically) the second lowest bidder would win. Additional measures used to control performance risk were prequalification of bidders, inclusion of quality dimensions other than price in the award criteria, and a requirement that the winning bidder give a financial guarantee (typically $5 \%$ of its bid).

The bid-envelopes received were opened and examined at a public event. The awardee could be awarded a contract for at most 4 years, although contracts for services were typically of much shorter duration. With some exceptions (e.g. when security or public safety could be jeopardized) the identity and bid of the winning bidder were published in the contract results notice.

Cost savings occurred whenever the lowest bid was lower than the cost estimate. These savings represent an efficiency gain from competitive source selection which can be ascribed, ultimately, to the decrease in production costs brought about by competitive pressure between 
producers (Leibenstein 1966). ${ }^{4}$ In the case of the SAF, these savings cannot be properly viewed as deriving from outsourcing, as they did not stem from the substitution of in-house production by more efficient, contracted-out provision. As pointed out by Fernández Roca (2011), the outsourcing of support services such as maintenance of building installations, restaurant and food serving, and cleaning spread as a consequence of the reduction in the number of recruits that followed the abolition of compulsory military service on January 1, 2002. As a matter of fact, coinciding with this reduction in personnel the SAF budget for procuring commercial services grew from $€ 47.9$ million in 1997 to $€ 121.0$ million in 2002 , and to $€ 137.4$ million in 2015 (all these figures are expressed in 2015 euros), accounting respectively for $0.61,1.48$, and $2.38 \%$ of the Spanish Ministry of Defense budget. ${ }^{5}$

\section{DATA AND VARIABLES}

We analyze 515 procurements of services pertaining to 256 contracting dossiers undertaken by the SAF in the period 2012-2015. Specifically, the contract notices for these dossiers were published between January 1, 2012 and December 31, 2015, and procurements were awarded before June 1, 2016. This limit on the awarding date excluded very few (if any) of the procurement procedures started in the last months of 2015: 50\% of the procurements whose contract notices were published in 2012-2014 were awarded within 83 days, 90\% within 143

\footnotetext{
${ }^{4}$ In the words of Carrick (1988), since competition stimulates the quest for better production methods, "the winning bidder usually acquired some unique insight on how to perform the contractual task."

${ }^{5}$ Authors' calculations using data from Oficina Presupuestaria, Dirección General de Asuntos Económicos, Ministerio de Defensa. The amount spent on commercial services corresponds to the budget item "Services performed by other companies and professionals."
} 
days, and 95\% within 184 days (Table 2 below shows the distribution of sample procurements by year of contract notice).

The 256 contracting dossiers included in this study represent $47.2 \%$ of the 542 service contracting dossiers awarded through competitive bidding by the SAF in the period 2012-2015. The rest of the dossiers were discarded for several reasons: In 226 cases cost savings were not possible, either because the cost estimate represented a commitment of funds to be used to pay the contractor's invoices ${ }^{6}$ or to subsidize the price of a service, or because the dossiers involved special administrative contracts, which entail no cost for the government since the price of the service is paid for by the end user (e.g. the contract for managing a base cafeteria). A further 14 dossiers were dropped on the grounds that they were canceled before awarding, 31 for having incomplete or inconsistent data (including the cap on the savings rate explained below), and 15 because their procurements were declared void. Table 1 presents a frequency distribution of contracting dossiers by type, sample selection status, and year.

The data on the sample of procurements was compiled expressly for this study from the information stored in the Public Sector Contracting Platform (PLACE in Spanish), accessed at https://contrataciondelestado.es/wps/portal/plataforma. PLACE is the national advertising website for Spanish government agencies to post contract notices, legal and technical tender information sheets, and contract results. These documents were personally read by the first author, and the information obtained was stored as a set of variables whose definition is outlined below; a more detailed definition plus some descriptive statistics are presented in Table 2.

The explaining variable is "Savings from a procurement". Following Snyder et al. (2001), savings are calculated as the difference between the cost estimate and the winning bid

\footnotetext{
${ }^{6}$ These contracts were awarded on the basis of unit prices for single services without specifying the quantity of single services to be procured.
} 
(both inclusive of VAT) divided by the contract term measured in years. As the model for estimating savings is nonlinear, we have removed from the sample those procurements whose savings (expressed as a proportion of the cost estimate) were above the 95th percentile of the savings distribution: Very high savings are likely to be the result of mismeasuring the general market price of the service to be procured, which introduces measurement error into the explaining variable (as well as into an explanatory variable). In the surviving set of 515 procurements, annual savings totaled $€ 24.6$ million. Expressed as a proportion of the cost estimate, savings ranged from $0 \%$ to $57 \%$, and averaged $17.9 \%$. This figure is in line with the international evidence on competitive bidding cited in the Introduction, but is substantially higher than the domestic evidence on savings from centralized procurement.

As a measure of the extent of bid rigging in SAF's service contracting, we calculated the percentage of procurements where the winning bid was within $1 \%$ of the cost estimate. This “collusive marker” (Harrington 2008) derives from McAfee and McMillan's (1992) analysis of bidding behavior at first-price sealed-bid auctions. McAfee and McMillan show that when all bidders collude, the winning bid clusters at the reserve price, whether the cartel is blocked from undertaking interfirm transfers or not. While low savings are of course consistent with interdependent though unilateral conduct (e.g. see Marshall and Marx 2012, p. 13), they suggest instances where competition between providers may be low. In our sample, the resulting figure was $12.4 \%$, which is about half the percentage found in settings where collusion has been found to be common (cf. McAfee and McMillan 1992). Furthermore, the figure was much lower (5.2\%) among the 135 procurements awarded using the lowest cost criterion.

The explanatory variables for savings can be classified as characteristics of the procurement, of the contracting agency, and of the service. The characteristics of the procurement are represented by a quadratic function of the natural logarithm of the cost estimate 
(also expressed on an annual basis), ${ }^{7}$ the percentage weight given to price in the award criteria (which is the essential difference between the lowest cost and best economic value systems), a variable indicating urgent procurements, a measure of bid screening intensity by the contract awarding committee, an indicator for whether the contract allows for extra payments, and the procurement's vintage as measured by year dummies. The characteristic of the contracting agency is the number of sample procurements conducted. The characteristics of the service are captured broadly by service-type fixed effects.

There are a number of reasons to adopt these factors as explanatory variables. First, Snyder et al. (2001) find that savings (i) rise more than proportionally to function size; (ii) vary across service types (being lower on average in the case of services whose output is harder to quantify); and (iii) do not diminish as time passes (no evidence if found of "cherry picking", i.e. that the services that generate the highest savings are selected for procurement first). Second, when procurement is deemed urgent the period for sending bids is reduced from 15 days to just 8 days, which might induce the participation of fewer bidders and/or less intense bidding between participants, resulting in higher winning bids and lower savings. Third, having conducted more procurements could help contracting agencies to judge the cost estimate more accurately, so we wonder whether savings may be affected by this potential "learning-bydoing" effect, and if so in which direction.

Finally, Goldberg (1977) and Spulber (1990) argue the existence of a trade-off between price and quality in first-price auctions, whereby savings are obtained partly at the expense of diminished performance. Although the empirical evidence on this issue is not conclusive (e.g. see Domberger et al. 1995, Cameron 2000, and Decarolis 2014), it is conceivable that an

\footnotetext{
${ }^{7}$ As in the paper by Snyder et al. (2001), the fit in the savings regression was much better with the cost estimate entering in log form.
} 
increase in the time taken to award the contract by the awarding committee comes with the benefit of selecting a more reliable contractor, but also at the expense of reducing savings (Decarolis 2014). In the same vein, cost overruns were generally not allowed by the 2011 law, ${ }^{8}$ but when the contract length exceeded one year the award price could be increased for reasons stated in the contract itself. In these cases, as suggested by Goldberg (1977), the broader prospect of extra payments after the contract was awarded might induce more aggressive bidding at the time of contracting and therefore higher savings.

For a subsample of 368 procurements, the information stored in PLACE includes the number of bidders $(n)$. Thus, when fitting the econometric model into this subsample, a quadratic function of $n$ is also included among the explanatory variables. As explained in Pinkse and Tan (2005), in conditionally independent private-value (CIPV) first-price auctions, an increase in $n$ could lead to less aggressive bidding if bidders internalize the "affiliation effect", namely that the distribution of rivals' production costs has more mass at higher costs than expected by the winning bidder prior to bidding. ${ }^{9}$ However, as $n$ becomes larger the more aggressive bidding induced by the presence of more rivals (the "competition effect") eventually dominates and the bid function is again decreasing in $n$. Although the relationship between the expected procurement price and $n$ is theoretically unclear, the quadratic specification allows the possibility of a varying empirical effect of $n$ on savings.

\footnotetext{
${ }^{8}$ Except when the original project contained errors or it was found convenient to accommodate innovations available after awarding the contract, with a maximum of $10 \%$ of the award price. ${ }^{9}$ The affiliation effect can also occur in common-value models. We think however that the CIPV paradigm may better suit service procurement auctions since we view production costs as different though related across bidders.
} 
When fitting the econometric model in the subsample, no special estimation technique is used: The fact that the savings variable itself appears to be irrelevant in a probit model for the observability of $n,{ }^{10}$ plus the fact that the average number of bidders (3.0) closely resembles that observed in other samples of government service procurements (e.g. see Li and Zheng 2009) leads us to believe that the information on $n$ is missed exogenously. Descriptive statistics for the subsample are also presented in Table 2.

\section{ECONOMETRIC MODEL}

Our empirical strategy is to specify, estimate, and test a regression model of savings (denoted by $y$ ) on the set of explanatory variables $(\mathbf{x})$. We do not analyze the cancellation/completion outcome of a procurement due to the small number of canceled procurements in our sample. Nor do we allow separate mechanisms to determine whether $y=0$ or $y>0$ and the magnitude of $y$ whenever $y>0$ due to the small number of cases with $y=0$ in our data (only 21 procurements present zero savings).

We assume that the conditional expectation of $y$ given $\mathbf{x}$ follows the Box-Cox like model proposed by Wooldridge (1992):

$$
\begin{array}{rlrl}
E(y \mid \mathbf{x}) & =[1+\lambda \mathbf{x} \boldsymbol{\beta}]^{1 / \lambda}, & \lambda \neq 0 \\
& =\exp (\mathbf{x} \boldsymbol{\beta}), \quad \lambda=0,
\end{array}
$$

\footnotetext{
10 The probit estimation included the above-mentioned explanatory variables as additional regressors, and its $R$-squared, calculated as one minus the ratio of the log likelihood of the fitted function to the log likelihood of a function with only an intercept, was .42 . The likelihood of observing the number of bidders increased with the weight for price and the time elapsed, among other factors.
} 
with $\mathbf{x} \equiv\left(1, x_{2}, \ldots, x_{K}\right)$, where the inequality $1+\lambda \mathbf{x} \boldsymbol{\beta} \geq 0$ (with strict inequality for $\lambda<0$ ) must hold for all relevant values of $\mathbf{x}$. This model is attractive in that it ensures positivity for any value of $\mathbf{x}$ and any parameter values $\boldsymbol{\beta}$ and $\lambda$. Furthermore, it nests popular alternatives for analyzing nonnegative explaining variables, such as exponential $(\lambda=0)$ and linear $(\lambda=1)$ regressions, so it provides a unified framework for testing particular, simpler functional forms.

On the other hand, it is well-known that the $t$-statistics for the estimated slope coefficients $\hat{\beta}_{2}, \ldots, \hat{\beta}_{K}$ are not invariant to the scaling of $y$ whenever $\lambda$ is estimated along with $\boldsymbol{\beta}$. The solution to this problem proposed by Wooldridge (1992) assumes $P(y>0)=1$, which does not hold in this study. But since the estimate of $\lambda$ plus its standard error is invariant to the scaling of $y$, we applied the following procedure to estimate (2.1)-(2.2): Firstly, we estimated jointly $\boldsymbol{\beta}$ and $\lambda$ to obtain an idea of the population value of $\lambda$. Then we estimated restricted versions of (2.1)-(2.2) in which the value of $\lambda$ was set to be equal to a subset of values taken from the confidence interval of $\hat{\lambda}$, using Schwarz's (1978) Bayesian information criterion (BIC) to select among these restricted models. ${ }^{11}$ (Previewing the results, the model with the lowest BIC has $\lambda=0$.)

Estimations were conducted using a quasi-maximum likelihood estimator (QMLE) in the linear exponential family (LEF) of probability distributions. In comparison with MLEs such as Tobit, QMLEs in the LEF are attractive in that they are robust to distributional misspecifications other than the conditional mean (Gourieroux et al. 1984). In our samples, indeed, conditional moment tests conducted after Tobit estimation (Pagan and Vella 1989) detected departures of

\footnotetext{
${ }^{11} \mathrm{BIC}$ is preferred to other popular information criteria when some modeling alternatives are nested (Nishii 1988). Granger et al. (1995) provide a critical assessment of model selection procedures based upon information criteria.
} 
the errors from normality and homoskedasticity $(p$-values $<.01) .{ }^{12}$ Weighted linear/nonlinear least squares estimators can also be consistent under less than full distributional assumptions and asymptotically as efficient as QMLEs, but they rely on two-step estimation and are, hence, computationally more burdensome. Symmetrically censored least squares and censored least absolute deviations are useful whenever $y$ is truly censored, but less so when interest lies in estimating properties of $E(y \mid \mathbf{x})$.

The particular QMLE utilized in this study is the exponential QMLE. Wooldridge (1992) provides formulae for the joint exponential QMLE of $\boldsymbol{\beta}$ and $\lambda$. Here, we focus on the exponential QMLE of $\boldsymbol{\beta}$ given $\lambda$. Most of the following formulae are simple adaptations of those derived by Wooldridge (1992).

Let $m\left(\mathbf{x}_{i}, \boldsymbol{\beta} ; \lambda\right)$ represent the conditional mean function (2.1)-(2.2) for procurement $i$, $i=1, \ldots, N$, with $\lambda$ set to a given value. $\hat{\boldsymbol{\beta}}$ is obtained by maximizing

$$
\ell_{i}(\boldsymbol{\beta})=-y_{i} / m\left(\mathbf{x}_{i}, \boldsymbol{\beta} ; \lambda\right)-\ln \left[m\left(\mathbf{x}_{i}, \boldsymbol{\beta} ; \lambda\right)\right]
$$

Under correct specification of $m\left(\mathbf{x}_{i}, \boldsymbol{\beta} ; \lambda\right)$ plus standard regularity conditions (see Gourieroux et al. 1984), $\hat{\boldsymbol{\beta}}$ is consistent and asymptotically normal.

Additionally, the exponential QMLE implicitly assumes a nonconstant conditional variance of $y$,

$$
\operatorname{var}(y \mid \mathbf{x})=[m(\mathbf{x}, \boldsymbol{\beta} ; \lambda)]^{2}
$$

which can result in efficiency gains with respect to ordinary linear/nonlinear least squares. Although the functional form (4) may be reasonable for nonnegative continuous variables

\footnotetext{
${ }^{12}$ As recommended by Drukker (2002) and Wilhelm (2008), the sampling distributions of the test statistics were approximated with the parametric bootstrap.
} 
(Wooldridge 2010, p. 741), our inference is robust to violations of (4): The estimated variance matrix of $\hat{\boldsymbol{\beta}}$ is calculated as ${ }^{13}$

$$
\hat{\mathrm{V}}(\hat{\boldsymbol{\beta}})=\{N /(N-1)\} \hat{\mathbf{A}}^{-1} \hat{\mathbf{B}} \hat{\mathbf{A}}^{\prime-1},
$$

where the term in braces is a finite-sample adjustment implemented by the software package

Stata,

$$
\hat{\mathbf{A}}=\sum_{i} E\left[\left.\frac{\partial \mathbf{s}_{i}}{\partial \boldsymbol{\beta}^{\prime}}\right|_{\hat{\boldsymbol{\beta}}} \mid \mathbf{x}_{i}\right], \quad \hat{\mathbf{B}}=\sum_{i} \mathbf{s}_{i} \mathbf{s}_{i}^{\prime},
$$$$
\mathbf{s}_{i} \equiv \partial \ell_{i}(\boldsymbol{\beta}) / \partial \boldsymbol{\beta}=\left[\partial m\left(\mathbf{x}_{i}, \boldsymbol{\beta} ; \lambda\right) / \partial \boldsymbol{\beta}\right]\left[y_{i}-m\left(\mathbf{x}_{i}, \boldsymbol{\beta} ; \lambda\right)\right] /\left[m\left(\mathbf{x}_{i}, \boldsymbol{\beta} ; \lambda\right)\right]^{2} \text {, and }
$$

$$
\begin{gathered}
\partial m\left(\mathbf{x}_{i}, \boldsymbol{\beta} ; \lambda\right) / \partial \boldsymbol{\beta}=[1+\lambda \mathbf{x} \boldsymbol{\beta}]^{\{(1 / \lambda)-1\}} \mathbf{x}^{\prime}, \quad \lambda \neq 0 \\
\partial m\left(\mathbf{x}_{i}, \boldsymbol{\beta} ; \lambda\right) / \partial \boldsymbol{\beta}=\exp (\mathbf{x} \boldsymbol{\beta}) \mathbf{x}^{\prime}, \quad \lambda=0 .
\end{gathered}
$$

$\sum_{i=1}^{N} \ell_{i}(\boldsymbol{\beta})$ was maximized in Stata (Version 11) using the command $m l$ and providing the optimization routine analytical first and expected second derivatives of the objective function (as in Mantel and Myers 1971). The QML estimates were obtained using the NewtonRaphson algorithm in conjunction with the starting values recommended by Mantel and Myers (1971). Convergence was accepted when both the scaled gradient and the relative change in the coefficient vector from one iteration to the next were less than $10^{-8}$. When $\lambda$ was estimated along with $\boldsymbol{\beta}$, maximization proceeded in a similar fashion except that the optimization routine used numerical first and second derivatives of the objective function.

\section{ESTIMATION RESULTS}

The joint exponential QMLE of $\boldsymbol{\beta}$ and $\lambda$ run on the full sample yielded $\hat{\lambda}=.118$, robust S.E. $=.089$, with a $95 \%$ confidence interval (CI) of -.056 to .292. In the subsample, $\hat{\lambda}=.108$,

\footnotetext{
${ }^{13}$ Wooldridge (2010) calls (5) a semirobust variance matrix estimator, as it assumes correct specification of $m\left(\mathbf{x}_{i}, \boldsymbol{\beta} ; \lambda\right)$.
} 
robust S.E. $=.176$, implying a $95 \%$ CI of -.237 to .453 . Setting the value of $\lambda$ to be equal to each value in the set $\{-0.2,-0.1,0,0.1,0.2,0.3,0.4\}$, which summarizes the widest of the above-mentioned CIs, we maximized $\sum_{i=1}^{N} \ell_{i}(\boldsymbol{\beta})$ by the method explained in the previous section. Table 3 presents the BIC values achieved by the restricted models. In both the full sample and the subsample the exponential regression model $(\lambda=0)$ was the best data-fitting option, with BIC values increasing monotonically as $\lambda$ deviated from 0 .

\subsection{Beta Coefficients}

The exponential regression estimates of $\boldsymbol{\beta}$ are given in Table 4. Column (1) presents the estimates obtained in the full sample, whereas columns (2) and (3) show, respectively, the estimates obtained in the subsample first excluding and then including the quadratic function of $n$ in order to assess the impact of including in $\mathbf{x} n$. At the bottom of each column in Table 4 the $p$-value of the robust Lagrange Multiplier (LM) test for $\lambda=0$ developed in Wooldridge (1992) is shown. This specification test assesses the validity of the exponential regression form against the more general function (2.1)-(2.2). In all three cases, the exponential form is not questioned at standard significance levels, although the non-rejection of $\lambda=0$ is held with more confidence when $\mathbf{x}$ includes information on $n$.

The three sets of estimates of $\boldsymbol{\beta}$ presented in Table 4 tell a rather consistent story in terms of sign and statistical significance. At the 5\% level the cost estimate, the weight given to price in the award criteria, and the number of weeks taken to announce the identity of the winning bidder all have positive effects on savings. The positive effect of weeks taken to award does not conform to the pattern discussed in Section 3. However, it should not be interpreted causally but rather as reflecting that higher savings are derived from procurements that take longer to award. At least in part, this is due to the fact that the winning bid is seldom disqualified 
for being abnormally low. ${ }^{14}$ But since there might be unobserved factors simultaneously affecting the level of savings and the screening intensity (e.g. mismeasurement of the general market price of the service), we tested for endogeneity of the weeks to award variable. To that end, we included in $\mathbf{x}$ the residual from a linear regression of weeks to award on the other explanatory variables plus the square of the weight given to price, as it turns out that the effect of the weight of price on weeks to award is U-shaped. We then tested the statistical significance of the residual term using a robust Wald test (Wooldridge 2010, p. 742). In all three cases shown in Table 4, the residual was statistically insignificant (the test $p$-value ranged from .23 to .53 ).

At the $5 \%$ level, the number of procurements conducted by the contracting agency and the variable indicating procurement for hotel/restaurant services exert negative effects on savings. With other factors held unchanged, procurements conducted by smaller agencies generate higher savings on average, possibly because smaller agencies tend to overestimate the general market prices of services in their cost estimates. Savings in procurements for hotel/restaurant services are, as a rule, lower than savings in procurements for maintenance or other personal services. To the extent that the output of hotel/restaurant services is harder to quantify, these results seem to conform to the pattern observed by Snyder et al. (2001).

The binary variables indicating urgent procurements, contracts that allow for extra payments, and the year of the contract notice have no significant effects on savings, in the last two cases mainly because their effects are measured imprecisely. We find the lack of effect on

${ }^{14}$ A total of 96 awarding committee meeting minutes (pertaining to the same number of procurements) were published in PLACE. The 13 among them which contain a request to justify prices took, on average, 10.1 weeks to award, whereas the other 83 took 5.9 weeks. Only in 3 cases was the winning bidder disqualified, which generated an $11 \%$ reduction in savings on average. 
savings of the urgent indicator particularly noteworthy even before accounting for differences in the number of bidders, which seems to indicate that bidders search effectively for bid submission opportunities.

The number of bidders has a quadratic effect on savings that gives rise to an inverted Ushaped relationship between $n$ and savings. On average, savings increase with $n$ until the procurement involves 16 bidders, and decrease from there on. But only two procurements included in the subsample involved more than 16 bidders, so savings are actually increasing with $n$ for almost all of the observed range of this variable (although at a decreasing rate). Hence, restricting the number of bidders will not generally benefit the government because it will generally reduce savings. In line with this conclusion, the new Spanish procurement law (which is a transposition of the European Union procurement directives adopted in 2014) seeks to stimulate formally advertised procurement in lieu of negotiated procurement.

\subsection{Average Marginal Effects}

Table 5 presents average marginal effects (AMEs) calculated from the exponential regression estimates of $\boldsymbol{\beta}$. Letting $\mathbf{x}_{(k)}$ and $\boldsymbol{\beta}_{(k)}$ denote the vectors $\mathbf{x}$ and $\boldsymbol{\beta}$ with the $k$ th explanatory variable removed, the marginal effect of $x_{k}$ on $E(y \mid \mathbf{x})$ is given by

$$
\Delta E(y \mid \mathbf{x})=\exp \left(\mathbf{x}_{(k)} \boldsymbol{\beta}_{(k)}+\beta_{k}\right)-\exp \left(\mathbf{x}_{(k)} \boldsymbol{\beta}_{(k)}\right)
$$

when $x_{k}$ is binary, and

$$
\frac{\partial E(y \mid \mathbf{x})}{\partial x_{k}}=\exp (\mathbf{x} \boldsymbol{\beta}) \beta_{k}
$$

when $x_{k}$ is continuous. For quadratic functions of $x_{k}$, the marginal effect is given by

$$
\frac{\partial E(y \mid \mathbf{x})}{\partial x_{k}}=\exp (\mathbf{x} \boldsymbol{\beta})\left[\beta_{k}+2 \beta_{k+1} x_{k}\right],
$$


where $\beta_{k+1}$ is the coefficient associated with $x_{k}^{2}$. AMEs are estimated by plugging $\hat{\boldsymbol{\beta}}$ into these expressions and then averaging across observations, with standard errors calculated using the delta method. For the two sets of binary variables representing year and service-type fixed effects, AMEs are calculated by zeroing out all of the dummies in the set and then setting the corresponding $x_{k}$ to 1 for all observations.

Annual savings are estimated to grow on average by $€ 1,800-€ 1,900$ when the cost estimate increases by $€ 10,000$. This effect is very precisely measured and attains statistical significance at the $1 \%$ level. The implied elasticity of annual savings with respect to the cost estimate (i.e. the elasticity with respect to the size of the procured function), calculated as

$$
\frac{\partial E(y \mid \mathbf{x})}{\partial \operatorname{cost}} \frac{\operatorname{cost}}{E(y \mid \mathbf{x})}=\beta_{\text {cost }}+2 \beta_{\text {cost }+1} \ln (\text { cost estimate }),
$$

is essentially the same across specifications: $1.00($ S.E. $=.03)$ in the full sample, 1.01 (S.E. $=$ $.03)$ in the subsample excluding the quadratic function of $n$, and $.99($ S.E. $=.03)$ when the quadratic function of $n$ is included. Thus, with other factors being unchanged, a $1 \%$ variation in the size of the function leads approximately to a $1 \%$ variation in annual savings, so that savings vary almost proportionally to size. A size elasticity of savings of 1 indicates that the practice of contracting agencies of dividing contracting dossiers into batches is irrelevant from the point of view of the total amount of savings attained. Moreover, it does not provide support for the opposite practice of centralizing the contracting out of services. This is a conclusion that the small savings rate achieved by centralizing the maintenance of helicopters used by the SAF already seemed to suggest.

For A-76 competitions, Snyder et al. (2001) estimate size elasticities of savings greater than unity, with size measured as the number of either civilian or military personnel employed in the function. They report that a $1 \%$ variation in civilian personnel leads approximately to a $1.08 \%$ variation in savings $($ S.E. $=.04)$, whereas the elasticity is $1.43 \%(S . E .=.10)$ with respect 
to variations in military personnel. Not surprisingly, our size elasticity of savings is smaller because it measures the response of savings to competition between bidders only, whereas the elasticities in Snyder et al. combine in their response variations in savings due to both competition and privatization. As such, the managerial lessons derived from our estimated response are better suited to the acquisition of functions that are not being provided in-house.

With other factors remaining unchanged, an increase of 10 percentage points in the weight given to price in the award criteria would increase annual savings in the neighborhood of $€ 5,600$ to $€ 7,700$. These estimates are quite precisely measured and attain statistical significance at the $1 \%$ level. Interpreted from the point of view of reducing the importance given to price, these estimates suggest an approximate value for the opportunity cost of (i.e. for the reduction in savings brought about by) introducing dimensions other than price in the award criteria. For example, as a consequence of introducing the Response and Standard dimensions in the scoring rule in expression (1), annual savings seem to have decreased by between $€ 16,800$ and $€ 23,100$ ceteris paribus, which corresponds to a 30 percentage point reduction in the weight given to price in the award criteria. The reason why the government may be willing to give up these savings may have to do with the reduction in the risk of poor performance that these additional dimensions may provide above and beyond the reduction permitted by other measures stipulated in the law.

The AME of the weight given to price diminishes somewhat after accounting for differences in the number of bidders across procurements. We used the Hausman test (Hausman 1978) to determine whether the two estimators of the marginal effect of the weight for price run 
on the subsample have different probability limits, and conclude that the null hypothesis of equal probability limits cannot be rejected at standard significance levels ( $p$-value .21$).{ }^{15}$

Procurements for hotel/restaurant services generate substantially smaller annual savings than comparable procurements for maintenance, with the reduction ranging from $€ 21,900$ to $€ 32,500$ depending on the specification. Hausman test results marginally question whether the two estimators for the marginal effect of the hotel/restaurant indicator run on the subsample have equal probability limits ( $p$-value .06), which suggests that a fraction (to be more precise, about one third) of the reduction in savings is due to the lower number of bidders who participate on average in procurements for hotel/restaurant services.

The AME on annual savings of an additional bidder is $€ 8,900$. This effect is measured quite precisely and attains statistical significance at the $1 \%$ level. Figure 1 shows the marginal effect on savings of an additional bidder calculated (with the finite-different method of expression (7)) at different values of the distribution of $n$, as well as error bars of twice the estimated robust standard error. The marginal effect on savings of an additional bidder is positive over the whole range shown, although the increase in the effect becomes successively smaller and indeed negative once 6 bidders are involved. In procurements involving three bidders (which is the minimum number of potential providers to be contacted in negotiated procurement), the evidence suggests that the presence of an additional bidder would increase annual savings by about $€ 10,100$, with a $95 \%$ CI of approximately $€ 6,800$ to $€ 13,300$.

\subsection{Sensitivity Analyses}

The negative association between the size of the contracting agency and savings might be the result of smaller agencies overestimating the general market price of the service to be procured.

\footnotetext{
${ }^{15}$ The variance of the difference between the two estimators was estimated using the paired bootstrap technique with 500 replications.
} 
But if this is so, the elasticity of savings with respect to the cost estimate could be biased. To assess the scope of this possible source of bias, we re-estimated the models in Table 4 with the $\log$ of the cost estimate and the square of that estimate interacted with the size of the agency (SIZE for brevity). In all three cases, the interaction terms $\ln ($ cost estimate)*SIZE and $(\ln (\text { cost estimate }))^{2} *$ SIZE were jointly statistically insignificant, with the test's $p$-value ranging from .70 in the full sample, to .13 in the subsample excluding the quadratic function of $n$, to .37 including the quadratic function of $n$. Consequently, the elasticity of savings with respect to the cost estimate, calculated now as

$$
\begin{aligned}
\frac{\partial E(y \mid \mathbf{x})}{\partial \cos t} \frac{\operatorname{cost}}{E(y \mid \mathbf{x})} & =\beta_{\text {cost }}+2 \beta_{\text {cost }+1} \ln (\text { cost estimate })+\beta_{\text {cost }+2} \mathrm{SIZE} \\
& +2 \beta_{\text {cost }+3} \ln (\text { cost estimate }) * \operatorname{SIZE}
\end{aligned}
$$

hardly changes: Given in the order of the columns of Table 4, the estimated elasticities are 1.01 $($ S.E. $=.03), 1.03($ S.E. $=.03)$, and $1.01($ S.E. $=.04)$.

More generally, one might wonder whether the quadratic functions of (the log of) the cost estimate and of $n$ are broad enough to contain good approximations of the truth. Moreover, variables such as the weight given to price, the screening intensity, and the size of the contracting agency were simply entered linearly in $\mathbf{x}$. To detect possible functional form misspecification in $\mathbf{x}$ we applied the extension of Ramsey's (1969) regression specification error test (RESET) to the exponential context described in Wooldridge (2010, p. 427). Thus, we added $(\mathbf{x} \hat{\boldsymbol{\beta}})^{2}$ and $(\mathbf{x} \hat{\boldsymbol{\beta}})^{3}$ to $\mathbf{x}$ and then tested their joint statistical significance with a heteroskedasticity-robust Wald statistic, which, under the assumption of no functional form misspecification, is asymptotically distributed as $\chi_{2}^{2}$. Each column of Table 4 presents the $p$ value for this test. In all cases, the claim of no functional form misspecification is well within confidence bounds. 
The quantity of information stored in PLACE generally increases over the years. Thus, for example, it is more likely to find information on $n$ for a procurement published in the period 2014-2015 than in 2012-2013. We wondered whether the same tendency might apply regarding the quality of the information available in PLACE. Hence, we re-estimated the models using the subsample of procurements published between January 1, 2014 and December 31, 2015. Table 6 presents the exponential regression AMEs calculated for these two years. ${ }^{16}$ The negative effect on savings of procurement for hotel/restaurant services becomes smaller and statistically insignificant, whereas the AME of an additional bidder is now somewhat larger. Again, however, the elasticity of savings with respect to the cost estimate is in the neighborhood of 1: Given in the usual order, it is estimated to be $1.03($ S.E. $=.04), 1.02($ S.E. $=.04)$, and 1.05 $($ S.E. $=.05)$.

\section{CONCLUSION}

This study provides novel and broad econometric evidence on the extent and determinants of cost savings in public procurement. By compiling data on the characteristics of 515 procurements of support services conducted by the Spanish Armed Forces between 2012 and 2015 , we find that savings averaged out at $17.9 \%$ of the cost estimate (or reserve price) for the service, which is in line with the international evidence on competitive bidding but is substantially higher than the domestic evidence on savings from centralized procurement.

Furthermore, by estimating a flexible nonlinear regression model of savings on a rich set of characteristics of procurements we find for example that savings rise proportionally to the cost estimate. This result concurs with the size elasticity of savings greater than 1 in Snyder et al. (2001), as we measured the response of savings to competition among bidders only,

\footnotetext{
${ }^{16}$ The dummy variable for whether the contract will allow for extra payments is removed from $\mathbf{x}$ because it was 1 in only two cases.
} 
whereas Snyder et al. developed estimates of the response of savings to variations in both competition and privatization. Our estimated size elasticity of 1 conveys important managerial lessons for the acquisition of services that are not being provided in-house: It indicates that the practice by contracting agencies of breaking up a large project into several smaller contracts is irrelevant from the point of view of the total savings attained, as is the opposite practice of centralizing the procurement of services.

To the best of our knowledge, we are the first to use actual data to estimate the opportunity cost of introducing dimensions in addition to price in the contract award criteria, which is the distinctive feature of the European Union's best economic value award system. Our most reliable estimates suggest that a reduction of 10 percentage points in the weight given to price in the award criteria reduces annual savings by approximately $€ 7,000$. Our results also indicate that restricting the number of bidders reduces savings for almost all of the observed range of number of bidders, which supports the limitation of the use of negotiated procurement in lieu of more formally advertised procurement. 


\section{REFERENCES}

Cameron, Lisa J. 2000. Limiting buyer discretion: Effects on performance and price in longterm contracts. American Economic Review 90:265-281.

Carrick, Paul M. 1988. New evidence on government efficiency. Journal of Policy Analysis and Management 7:518-528.

Decarolis, Francesco. 2014. Awarding price, contract performance, and bids screening: Evidence from procurement auctions. American Economic Journal: Applied Economics 6:108-132.

Domberger, Simon, Christine Hall, and Eric Ah Lik Li. 1995. The determinants of price and quality in competitively tendered contracts. The Economic Journal 105:1454-1470.

Domberger, Simon, Paul H. Jensen, and Robin E. Stonecash. 2002. Examining the magnitude and sources of cost savings associated with outsourcing. Public Performance and Management Review 26:148-168.

Domberger, S., S.A. Meadowcroft, and D.J. Thompson. 1986. Competitive tendering and efficiency: The case of refuse collection. Fiscal Studies 7(4):69-89.

Drukker, David M. 2002. Bootstrapping a conditional moments test for normality after tobit estimation. The Stata Journal 2(2):125-139.

Fernández Roca, Juan Manuel. 2011. Viabilidad y costes de la externalización de servicios en el ámbito de las Fuerzas Armadas (Doctoral dissertation). Madrid. Ministerio de Defensa.

Goldberg, Victor P. 1977. Competitive bidding and the production of precontract information. Bell Journal of Economics 8(1):250-261.

Gourieroux, C., A. Monfort, and A. Trognon. 1984. Pseudo maximum likelihood methods: theory. Econometrica 52(3):681-700. 
Granger, Clive W.J., Maxwell L. King, and Halbert White. 1995. Comments on testing economic theories and the use of model selection criteria. Journal of Econometrics $67: 173-187$.

Gris González, Juan Carlos. 2012. La modificación de los contratos del Sector Público. Derecho Administrativo 28(September):1-35.

Harrington, Joseph E. Jr. 2008. Detecting cartels. In Paolo Buccirossi, ed., Handbook of Antitrust Economics, pp. 213-258. Cambridge: MIT Press.

Hausman, J.A. 1978. Specification tests in econometrics. Econometrica 46(6):1251-1271.

Leibenstein, Harvey. 1966. Allocative efficiency vs. "X-efficiency". American Economic Review 56(3):392-415.

Li, Tong and Xiaoyong Zheng. 2009. Entry and competition effects in first-price auctions: Theory and evidence from procurement auctions. Review of Economic Studies 76(4):1397-1429.

Lyon, Thomas P. 2006. Does dual sourcing lower procurement costs? Journal of Industrial Economics 54:223-252.

MacDonald, Peter. 2010. Economics of Military Outsourcing. PhD Dissertation. Department of Economics, University of York.

Mantel, Nathan and Max Myers. 1971. Problems of convergence of maximum likelihood iterative procedures in multiparameter situations. Journal of the American Statistical Association 66(335):484-491.

Marshall, Robert C. and Leslie M. Marx. 2012. The Economics of Collusion: Cartels and Bidding Rings. Cambridge and London: MIT Press.

McAfee, R. Preston and John McMillan. 1992. Bidding rings. American Economic Review 82(3):579-99. 
Nishii, R. 1988. Maximum likelihood principle and model selection when the true model is unspecified. Journal of Multivariate Analysis 27:392-403.

Pagan, Adrian and Frank Vella. 1989. Diagnostic tests for models based on individual data: A survey. Journal of Applied Econometrics 4(December):S29-S59.

Pinkse, Joris and Guofu Tan. 2005. The affiliation effect in first-price auctions. Econometrica 73(1):263-277.

Ramsey, J.B. 1969. Tests for specification errors in classical linear least-squares regression analysis. Journal of the Royal Statistical Society. Series B 31(2):350-371.

Schwarz, Gideon. 1978. Estimating the dimension of a model. The Annals of Statistics 6(2):461464.

Snyder, Christopher M., Robert P. Trost, and R. Derek Trunkey. 2001. Reducing government spending with privatization competitions: A study of the Department of Defense experience. Review of Economics and Statistics 83(1):108-117.

Spulber, Daniel S. 1990. Auctions and contract enforcement. Journal of Law, Economics, and Organization 6(2):325-344

Wilhelm, Mark Ottoni. 2008. Practical considerations for choosing between tobit and SCLS or CLAD estimators for censored regression models with an application to charitable giving. Oxford Bulletin of Economics and Statistics 70(4):559-582.

Wooldridge, Jeffrey M. 1992. Some alternatives to the Box-Cox regression model. International Economic Review 33(4):935-955.

Wooldridge, Jeffrey M. 2010. Econometric Analysis of Cross Section and Panel Data. Second edition. Cambridge, MA: The MIT Press. 
TABLE 1 -SERVICE CONTRACTING DOSSIERS AWARDED BY THE SPANISH ARMED FORCES THROUGH COMPETITIVE BIDDING, BY TYPE OF DOSSIER, SAMPLE SELECTION STATUS, AND YEAR

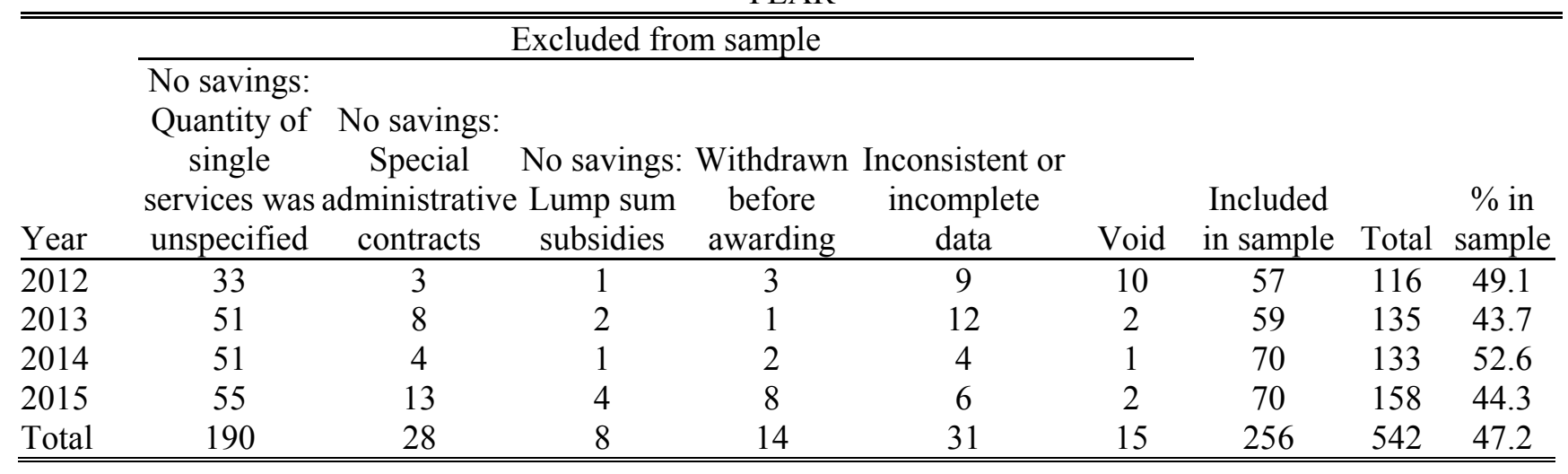




\begin{tabular}{|c|c|c|c|}
\hline Variable & Description & $\begin{array}{l}\text { Full sample, } N=515 \\
\text { Mean (S.D.) }\end{array}$ & $\begin{array}{l}\text { Subsample, } N=368 \\
\text { Mean (S.D.) }\end{array}$ \\
\hline Savings ${ }^{\mathrm{a}}$ & $\begin{array}{l}\text { Difference between the cost estimate and the lowest bid (both inclusive of VAT) divided by } \\
\text { the contract length, measured in } € 1,000 \text { s on an annual basis. }\end{array}$ & $47.83(128.10)$ & $54.83(145.20)$ \\
\hline Cost estimate $^{\mathrm{a}}$ & Cost estimate divided by the contract length, measured in $€ 10,000$ s on an annual basis. & $29.99(61.23)$ & $32.73(64.85)$ \\
\hline Weight for price ${ }^{b}$ & Percentage weight given to price in the award criteria, divided by 10 . & $7.18(2.24)$ & $7.46 * *(2.16)$ \\
\hline Urgent $^{\mathrm{c}}$ & Dummy variable $=1$ if procurement was deemed to be urgent. & 0.22 & $0.17 * * *$ \\
\hline Screening $^{\mathrm{a}}$ & $\begin{array}{l}\text { Difference (in weeks) between when the bids were opened by the awarding committee and } \\
\text { when the identity of the winning bidder was announced. }\end{array}$ & $6.07(4.79)$ & $6.39(5.34)$ \\
\hline Price amend ${ }^{\mathrm{b}}$ & Dummy variable $=1$ if the contract price could be altered for reasons stated in the contract. & 0.09 & 0.12 \\
\hline Year $2012^{\mathrm{c}}$ & Dummy variable $=1$ if the contract notice was published in 2012 & 0.22 & $0.10 * * *$ \\
\hline Year $2013^{\mathrm{c}}$ & Dummy variable $=1$ if the contract notice was published in 2013. & 0.30 & 0.30 \\
\hline Year $2014^{\mathrm{c}}$ & Dummy variable $=1$ if the contract notice was published in 2014. & 0.24 & 0.28 \\
\hline Year $2015^{\mathrm{c}}$ & Dummy variable $=1$ if the contract notice was published in 2015 & 0.24 & $0.32 * * *$ \\
\hline Size of agency ${ }^{\mathrm{a}}$ & $\begin{array}{l}\text { Number of sample auctions managed by the agency which the observed auction belongs to, } \\
\text { divided by } 5 \text {. }\end{array}$ & $6.33(5.15)$ & $5.57 * * *(4.47)$ \\
\hline $\begin{array}{l}\text { Maintenance of } \\
\text { vehicles/apparatuses }\end{array}$ & ${ }_{\mathrm{c}}$ Dummy variable $=1$ if the contract was for repair or maintenance of vehicles or apparatuses. & 0.23 & 0.24 \\
\hline $\begin{array}{l}\text { Maintenance of } \\
\text { buildings }{ }^{c}\end{array}$ & Dummy variable $=1$ if the contract was for repair or maintenance of building installations. & 0.16 & 0.15 \\
\hline Hotel/Restaurant ${ }^{\mathrm{c}}$ & $\begin{array}{l}\text { Dummy variable }=1 \text { if the contract was for hotel, accommodation, restaurant, or food-serving } \\
\text { services. }\end{array}$ & 0.22 & 0.25 \\
\hline $\begin{array}{l}\text { Other personal } \\
\text { services }^{c}\end{array}$ & $\begin{array}{l}\text { Dummy variable }=1 \text { if the contract was for transportation, telecommunications, or training } \\
\text { services. }\end{array}$ & 0.15 & 0.14 \\
\hline Refuse $^{c}$ & Dummy variable $=1$ if the contract was for sewage, refuse, or cleaning services. & 0.09 & 0.07 \\
\hline Miscellaneous ${ }^{\mathrm{c}}$ & Dummy variable $=1$ if the contract was for other services. & 0.15 & 0.15 \\
\hline No. of bidders ${ }^{\mathrm{d}}$ & Includes bids above the cost estimate, presenting formal errors, or deemed abnormally low. & & $3.01(2.75)$ \\
\hline
\end{tabular}

Source: ${ }^{a}$ : Authors' calculations based on contract results notice data. ${ }^{\text {b}}$ : Tender information legal sheet. ${ }^{\mathrm{c}}$ : Contract notice. ${ }^{\mathrm{d}}$ : Contract results notice.

Notes: A Student's $t$ test was used to check whether a variable's mean in the subsample was statistically different from the point estimate of the same variable's mean calculated in the full sample; ** statistically different at $5 \%, * * *$ statistically different at $1 \%$. 
TABLE 3-BIC VALUES

\begin{tabular}{lcc}
\hline \hline$\lambda$ & Full sample, $N=515$ & Subsample, $N=368$ \\
\hline-0.2 & 4143.17 & 3010.29 \\
-0.1 & 4136.52 & 3007.16 \\
0 & 4126.45 & 2999.32 \\
0.1 & 4131.17 & 3004.48 \\
0.2 & 4131.99 & 3005.15 \\
0.3 & 4135.67 & 3007.83 \\
0.4 & 4142.48 & 3011.36 \\
\hline \hline \multirow{2}{*}{ Notes: } & BIC $=-2 \sum_{i=1}^{N} \ell_{i}(\boldsymbol{\beta})+\ln (N) q$, where $q=\operatorname{dim}(\boldsymbol{\beta})$ if \\
$\lambda=0$, and $q=\operatorname{dim}(\boldsymbol{\beta})+1$ if $\lambda \neq 0$.
\end{tabular}


TABLE 4-QML ESTIMATES OF ANNUAL SAVINGS (€1,000s). EXPONENTIAL REGRESSION $(\lambda=0)$. ESTIMATED COEFFICIENTS.

\begin{tabular}{|c|c|c|c|c|c|c|}
\hline \multirow[b]{2}{*}{ Explanatory variable } & \multicolumn{2}{|c|}{$\begin{array}{c}(1) \\
\text { Full sample }\end{array}$} & \multicolumn{2}{|c|}{$\begin{array}{c}(2) \\
\text { Subsample }\end{array}$} & \multicolumn{2}{|c|}{$\begin{array}{c}(3) \\
\text { Subsample }\end{array}$} \\
\hline & Coefficient & S.E. & Coefficient & S.E. & Coefficient & S.E. \\
\hline Ln of cost estimate & $1.027 * * *$ & .061 & $.988 * * *$ & .076 & $.842 * * *$ & .072 \\
\hline$(\mathrm{Ln} \text { of cost estimate })^{2}$ & -.006 & .012 & .004 & .015 & $.030^{* *}$ & .014 \\
\hline Weight for price $(\div 10)$ & $.116^{* * *}$ & .021 & $.138 * * *$ & .027 & $.121 * * *$ & .028 \\
\hline Urgent & -.105 & .102 & .007 & .125 & .004 & 137 \\
\hline Screening (weeks) & $.033 * * *$ & .008 & $.034 * * *$ & .009 & $.038 * * *$ & .009 \\
\hline Price amend & .220 & .185 & .267 & .200 & .142 & .215 \\
\hline Year 2013 & .019 & .108 & .027 & 181 & .082 & 197 \\
\hline Year 2014 & -.162 & .100 & -.104 & .174 & .012 & 192 \\
\hline Year 2015 & .042 & .106 & .093 & .162 & .214 & .175 \\
\hline Size of agency (procurements $\div 5$ ) & $-.026 * * *$ & .009 & $-.040 * * *$ & .012 & $-.038 * * *$ & .013 \\
\hline Maintenance of buildings & .011 & .092 & .102 & .112 & .087 & .115 \\
\hline Hotel/Restaurant & $-.768 * * *$ & .166 & $-.647 * * *$ & .196 & $-.444 * *$ & .226 \\
\hline Other personal services & .084 & .108 & $.325 * *$ & .138 & $.517 * * *$ & .139 \\
\hline Refuse & $-.390 * * *$ & .143 & -.203 & .178 & -.149 & .180 \\
\hline Miscellaneous services & $-.278 * *$ & .117 & -.276 & .149 & -.234 & .153 \\
\hline No. of bidders & & & & & $.207 * * *$ & .030 \\
\hline$(\text { No. of bidders) })^{2}$ & & & & & $-.007 * * *$ & .002 \\
\hline Intercept & -.170 & .209 & -.415 & .280 & $-.896 * * *$ & .322 \\
\hline Log likelihood & -2013 & & -1463. & & -1446 & \\
\hline LM test of $\lambda=0$ & {$[.15$} & & {$[.11]$} & & {$[.56]$} & \\
\hline Ramsey's (1969) RESET & {$[.30$} & & {$[.23]$} & & {$[.79]$} & \\
\hline Observations & 515 & & 368 & & 368 & \\
\hline
\end{tabular}

Notes: Standard errors are robust to arbitrary heteroskedasticity. Figures in brackets are $p$-values. Unreported categories: Year 2012, maintenance of vehicles/apparatuses. ** Significant at 5\%;*** significant at $1 \%$. 
TABLE 5-QML ESTIMATES OF ANNUAL SAVINGS ( $€ 1,000 \mathrm{~s})$. EXPONENTIAL REGRESSION $(\lambda=0)$. AVERAGE MARGINAL EFFECTS.

\begin{tabular}{|c|c|c|c|c|c|c|}
\hline \multirow[b]{2}{*}{ Explanatory variable } & \multicolumn{2}{|c|}{$\begin{array}{c}(1) \\
\text { Full sample }\end{array}$} & \multicolumn{2}{|c|}{$\begin{array}{c}(2) \\
\text { Subsample }\end{array}$} & \multicolumn{2}{|c|}{$\begin{array}{c}\text { (3) } \\
\text { Subsample }\end{array}$} \\
\hline & AME & S.E. & AME & S.E. & $\mathrm{AME}$ & S.E. \\
\hline Cost estimate $(€ 10,000 \mathrm{~s})$ & $1.812 * * *$ & .078 & $1.923 * * *$ & .099 & $1.894 * * *$ & .100 \\
\hline Weight for price $(\div 10)$ & $5.572 * * *$ & 1.066 & $7.702 * * *$ & 1.613 & $6.689 * * *$ & 1.675 \\
\hline Urgent & -4.920 & 4.719 & .397 & 6.987 & .238 & 7.549 \\
\hline Screening (weeks) & $1.576^{* * *}$ & .397 & $1.925 * * *$ & .520 & $2.095 * * *$ & .528 \\
\hline Price amend & 11.483 & 10.302 & 16.437 & 13.393 & 8.199 & 12.978 \\
\hline Year 2013 & .935 & 5.336 & 1.507 & 10.031 & 4.281 & 10.149 \\
\hline Year 2014 & -7.291 & 4.482 & -5.425 & 9.228 & .591 & 9.607 \\
\hline Year 2015 & 2.070 & 5.279 & 5.359 & 9.118 & 11.877 & 9.381 \\
\hline Size of agency (procurements $\div 5$ ) & $-1.259 * * *$ & .451 & $-2.257 * * *$ & .745 & $-2.113 * * *$ & .781 \\
\hline Maintenance of buildings & .689 & 5.588 & 7.075 & 7.933 & 5.525 & 7.448 \\
\hline Hotel/Restaurant & $-32.479 * * *$ & 6.855 & $-31.648 * * *$ & 9.359 & $-21.916 * *$ & 10.572 \\
\hline Other personal services & 5.277 & 6.858 & $25.399 * *$ & 11.389 & $41.317 * * *$ & 12.430 \\
\hline Refuse & $-19.550 * * *$ & 6.801 & -12.154 & 10.063 & -8.458 & 9.708 \\
\hline Miscellaneous services & $-14.714 * *$ & 6.208 & -15.927 & 8.658 & -12.755 & 8.377 \\
\hline No. of bidders & & & & & $8.906 * * *$ & 1.301 \\
\hline Observations & 515 & & 368 & & 368 & \\
\hline
\end{tabular}


TABLE 6-QML ESTIMATES OF ANNUAL SAVINGS (€1,000s), YEARS 2014 AND 2015. EXPONENTIAL REGRESSION $(\lambda=0)$. AVERAGE MARGINAL EFFECTS.

\begin{tabular}{|c|c|c|c|c|c|c|}
\hline \multirow[b]{2}{*}{ Explanatory variable } & \multicolumn{2}{|c|}{$\begin{array}{c}\text { (1) } \\
\text { Full sample }\end{array}$} & \multicolumn{2}{|c|}{$\begin{array}{c}(2) \\
\text { Subsample }\end{array}$} & \multicolumn{2}{|c|}{$\begin{array}{c}(3) \\
\text { Subsample }\end{array}$} \\
\hline & AME & S.E. & AME & S.E. & AME & S.E. \\
\hline Cost estimate $(€ 10,000 \mathrm{~s})$ & $1.823 * * *$ & .123 & $1.819 * * *$ & .137 & $1.901 * * *$ & .135 \\
\hline Weight for price $(\div 10)$ & $8.019 * * *$ & 2.034 & $8.526 * * *$ & 2.356 & $7.218 * * *$ & 2.471 \\
\hline Urgent & -1.013 & 7.305 & -1.054 & 8.423 & -3.311 & 8.892 \\
\hline Screening (weeks) & .956 & .635 & 1.074 & .664 & .570 & .687 \\
\hline Year 2015 & 8.770 & 5.967 & 9.719 & 6.466 & 8.026 & 6.504 \\
\hline Size of agency (procurements $\div 5$ ) & $-2.040 * * *$ & .753 & $-2.327 * * *$ & .874 & $-2.422 * * *$ & .909 \\
\hline Maintenance of buildings & 13.745 & 7.714 & 17.448 & 9.308 & 1.756 & 8.764 \\
\hline Hotel/Restaurant & $-21.803 * *$ & 9.820 & -19.157 & 11.433 & -13.957 & 13.314 \\
\hline Other personal services & $35.596 * *$ & 14.809 & $45.200 * * *$ & 17.419 & $49.212 * *$ & 19.922 \\
\hline Refuse & -2.613 & 10.096 & 2.756 & 12.813 & -11.680 & 9.490 \\
\hline Miscellaneous services & -15.521 & 9.997 & -10.392 & 11.568 & -12.731 & 10.603 \\
\hline No. of bidders & & & & & $12.330 * * *$ & 3.256 \\
\hline Observations & 246 & & 222 & & 222 & \\
\hline
\end{tabular}


FIGURE 1-EFFECT OF AN ADDITIONAL BIDDER ON SAVINGS, BY NUMBER OF BIDDERS

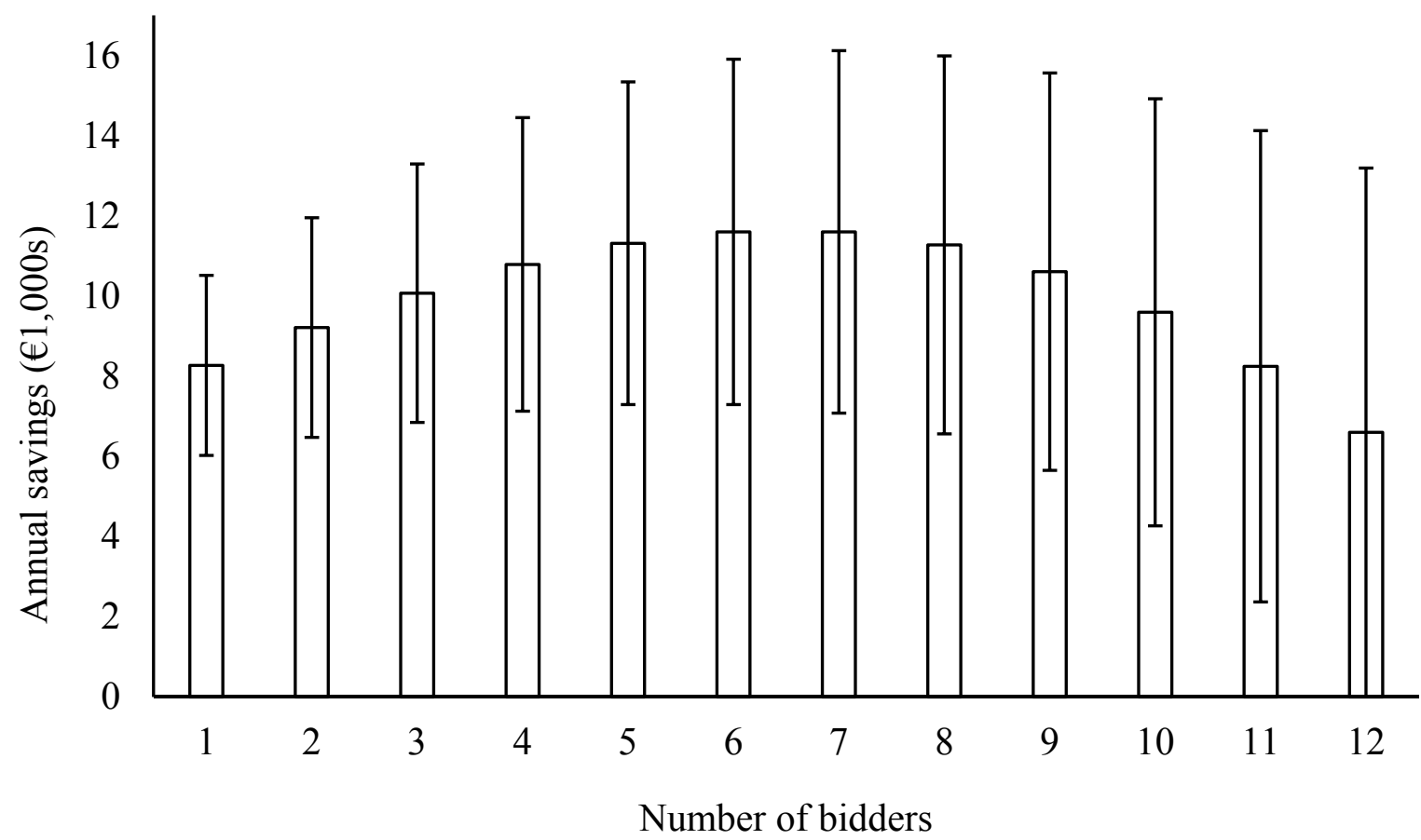

Notes: Error bars show twice the estimated heteroskedasticity-robust standard error. 